\title{
Publisher Correction: Tracing the transitions from pluripotency to germ cell fate with CRISPR screening
}

\author{
Jamie A. Hackett1,2,3, Yun Huang (1) 1,3, Ufuk Günesdogan 1,3,4, Kristjan A. Gretarsson ${ }^{2}$, Toshihiro Kobayashi, ${ }^{1,3,5}$ \& \\ M. Azim Surani ${ }^{1,3}$
}

Correction to: Nature Communications; https://doi.org/10.1038/s41467-018-06230-0; published online 16 October 2018

The original version of this Article contained errors in the author affiliations.

Ufuk Günesdogan was incorrectly associated with Center for Genetic Analysis of Behaviour, National Institute for Physiological Sciences, 5-1 Higashiyama Myodaiji, Okazaki, Aichi 444-8787, Japan and Toshihiro Kobayashi was incorrectly associated with Department of Developmental Biology, University of Göttingen, Göttingen Center for Molecular Biosciences, Justus-von-Liebig Weg 11, 37077 Göttingen, Germany.

This has now been corrected in both the PDF and HTML versions of the Article.

Published online: 11 December 2018

\begin{abstract}
(i) Open Access This article is licensed under a Creative Commons Attribution 4.0 International License, which permits use, sharing, adaptation, distribution and reproduction in any medium or format, as long as you give appropriate credit to the original author(s) and the source, provide a link to the Creative Commons license, and indicate if changes were made. The images or other third party material in this article are included in the article's Creative Commons license, unless indicated otherwise in a credit line to the material. If material is not included in the article's Creative Commons license and your intended use is not permitted by statutory regulation or exceeds the permitted use, you will need to obtain permission directly from the copyright holder. To view a copy of this license, visit http://creativecommons.org/licenses/by/4.0/.
\end{abstract}

(C) The Author(s) 2018

\footnotetext{
${ }^{1}$ Wellcome Trust/Cancer Research UK Gurdon Institute, University of Cambridge, Tennis Court Road, Cambridge CB2 1QN, UK. ${ }^{2}$ Epigenetics and Neurobiology Unit, European Molecular Biology Laboratory (EMBL), via Ramarini 32, 00015 Rome, Italy. ${ }^{3}$ Department of Physiology, Development and Neuroscience, University of Cambridge, Downing Street, Cambridge CB2 3DY, UK. ${ }^{4}$ Department of Developmental Biology, University of Göttingen, Göttingen Center for Molecular Biosciences, Justus-von-Liebig Weg 11, 37077 Göttingen, Germany. ${ }^{5}$ Present address: Center for Genetic Analysis of Behaviour, National Institute for Physiological Sciences, 5-1 Higashiyama Myodaiji, 444-8787 Okazaki, Aichi, Japan. These authors contributed equally: Jamie A. Hackett, Yun Huang, Ufuk Günesdogan. The original article can be found online at https://doi.org/10.1038/s41467-018-06230-0. Correspondence and requests for materials should be addressed to J.A.H. (email: jamie.hackett@embl.it) or to M.A.S. (email: a.surani@gurdon.cam.ac.uk)
} 